Check for updates

Cite this: Food Funct., 2021, 12, 3939

\section{Optimization of the drying process of autumn fruits rich in antioxidants: a study focusing on rosehip (Rosa canina L.) and sea buckthorn (Elaeagnus rhamnoides (L.) A. Nelson) and their bioactive properties}

\author{
Cadmiel Moldovan, ${ }^{a}$ Mihai Babotă, (D) a Andrei Mocan, (D)*a,b Luigi Menghini, ${ }^{c}$ \\ Stefania Cesa, (D) Alexandru Gavan, ${ }^{a}$ Cristian Sisea, ${ }^{e}$ Dan C. Vodnar, ${ }^{f}$ \\ Maria Inês Dias, (DD ${ }^{9}$ Carla Pereira, (D) ${ }^{9}$ Isabel C. F. R. Ferreira, (DD ${ }^{9}$ Gianina Crişan ${ }^{a}$ and \\ Lillian Barros (D)*9
}

\begin{abstract}
Nowadays, it is very important to identify the traditional uses of different plants and to create the context in which new cultural or economic value is given to local resources. In this study, two wild fruits traditionally harvested in autumn in Romania were selected to investigate the effects of drying conditions on the chemical compositions and bioactivities exerted by the extracts and to select the best conditions in terms of air temperature and time of drying. The extracts obtained were assessed in terms of antioxidant capacity and enzyme inhibitory activity, and their main bioactive compounds were identified and quantified. The data presented in this article represent a step forward in applying this process on an industrial-scale.
\end{abstract}

Received 24th October 2020, Accepted 8th March 2021

DOI: $10.1039 / \mathrm{dOfo} 02783 a$

rsc.li/food-function leaves, flowers, and seeds of spontaneous shrubs and trees. In this context, this study was focused on evaluating the different biological properties of two wild fruits traditionally harvested in autumn. In particular, the properties of these plants can be suitable for possible use in the development of functional foods or for using as potential sources of natural antioxidants.

Rosa canina L., usually known as rosehip, is a perennial shrub in the Rosaceae family. The name of the species in Romanian is "Măceş" and it is found in all areas of the country. The fruits of this species are harvested by the Romanians and used for a broad range of meals.

Rosehip fruits are extensively used in folk medicine in different countries worldwide. Some of the traditional uses of the Rosa canina pseudofruits are: for prevention and treatment of common colds, infectious diseases, and vitamin C deficiency; for treatment of fever and gastric spams; in prevention of gastritis and gastric ulcers and as a laxative; and as an adjuvant therapy for gallstones and gallbladder discomforts, gout, arthritis, sciatica, inadequate peripheral circulation, and lung ailments. ${ }^{1}$ There are many uses of rosehip in Romanian folk medicine, such as fortifier for convalescents and anemics. The pseudofruits of Rosa canina are appreciated by Romanians for their high content of vitamin C. It was postulated that rosehips have a higher proportion of ascorbic acid (vitamin $\mathrm{C}$ ) than any other known and available vegetables or fruits. ${ }^{2}$ Moreover, they are considerably beneficial for human health because of their 
chemical composition rich in minerals, sugars, organic acids, phenolic compounds, carotenoids, and fatty acids.

Various extracts and isolated constituents from rosehip have been evaluated by a variety of in vitro and in vivo assays. The Rosa canina pseudofruits exerted various pharmacological effects in the prevention and/or treatment of a broad spectrum of ailments, such as infectious, cardiovascular, and kidney diseases, and diabetes, cancer, liver damage, obesity, and inflammation.

Another species traditionally harvested in Romania is sea buckthorn (Elaeagnus rhamnoides syn.: Hippophae rhamnoides), a thorny deciduous shrub native to Europe and Asia. In Greece, it was used as a diet for racehorses; hence, it got the former botanical name "Hippophae", which means "shiny". 3 Many medicinal preparations using different parts of the plant, from both cultivated and wild sources, have been used in clinics to treat burns, radiation damage, oral inflammation, and gastric ulcers in the former Soviet Republics and China. ${ }^{4}$ Beyond the medicinal use, the berries of sea buckthorn can be processed to make juice and jam, or to be used as flavoring agents of dairy products because of their unique taste. ${ }^{5}$

It is also a source of very important bioactive substances like vitamin $\mathrm{C}$, mineral elements, sugars, organic acids, free amino acids, large amount of carotenoids and vitamin E, volatile compounds, quercetin, myricetin and kaempferol, fatty acids, triacylglycerol, glycerophospholipids, phytosterols, zeaxanthin, esters, alpha-tocopherol, and phenolic compounds. ${ }^{3}$

A wide spectrum of pharmacological effects, including antioxidant, immunomodulatory, anti-atherogenic, anti-stress, hepatoprotective, radioprotective, and tissue repair activities have been recently reported. ${ }^{6,7}$

Generally, dehydration techniques are usually applied for the treatment of fruits, taking into account the conditions of the process to preserve the compounds of interest. One of the most traditional methods is dehydration in a conventional drying oven under different temperature and time conditions. ${ }^{8}$ However, due to the long drying time often required, these methods can cause hydrolysis, oxidation, and degradation of the compounds of interest. In this regard, the objectives of this research were to investigate the effects of the drying conditions on the total contents of phenolic and flavonoid compounds in the two traditionally used fruits in Romania and to select the best conditions in terms of air temperature and time of drying.

Phenolic compounds are defined as secondary metabolites which are derivatives of the pentose phosphate, shikimate, and phenylpropanoid pathways in plants. These compounds are one of the most widely occurring groups of phytochemicals and have physiological and morphological importance in plants. Moreover, phenolic compounds play an important role in growth and reproduction and can provide protection against predators and pathogens. ${ }^{9}$

Flavonoids can be defined as phenolic compounds with low molecular weights, secondary metabolites found in various plants. Flavonoids can occur in their free state or as glycosides. In the last years, the literature documented a broad spectrum of pharmacological actions on the diverse systems of the human body. Among these, we can mention the neuroprotec- tive and anti-convulsive effects on the CNS, prevention and treatment of cardiovascular diseases, and treatment of dyslipidemia and obesity. Recent studies have documented that flavonoids can act on the biological targets involved in type-2 diabetes, inflammation, and immune system processes. Furthermore, flavonoids can act as antitumoral, antimicrobial and antifungal agents. ${ }^{10}$ Considering all of these interesting properties, it is important to evaluate the total flavonoid content (TFC) of the studied extracts.

Fernandez-Panchon et al. reported in a comprehensive review paper that aimed to correlate the plants' phenolic composition with the antioxidant activity that the phenolic compounds in fruits and vegetables can exert an antioxidant activity both in vitro and in vivo. ${ }^{11}$ They also showed that the difference between in vivo antioxidant activities reported by various studies is due to the different analytical methods employed.

Some other recent studies aimed to assess the $\alpha$-glucosidase inhibitory activity of some phenolic phytochemical enriched plant extracts. They demonstrated that there is a direct link between the quantity of phenolic compounds and the inhibitory activity of $\alpha$-glucosidase. ${ }^{12}$

Even if these fruits are known to be rich in vitamin $\mathrm{C}$, we chose not to quantify this compound, but to assess the quantity of two parameters that are representatives of bioactive compounds in natural products. Furthermore, we emphasized the importance of optimizing the drying conditions by comparing the quality of dried fruits with the data found in the scientific literature. The comparison was made in terms of total phenolic and flavonoid contents and antioxidant activity. This article also emphasizes the effect of processing the plant materials, correlating the main pharmacological effects of the considered plant materials with the drying processes and extraction methods used.

\section{Materials and methods}

\subsection{Standards and reagents}

The reagents used in this study were: sodium carbonate, ferric chloride, 6-hydroxy-2,5,7,8-tetramethylchromane-2-carboxylic acid (Trolox) (97\%), diammonium 2,2'-azinobis(3-ethylbenzothiazoline-6-sulfonate) (ABTS) (>98\%), 2,2-diphenyl-1-(2,4,6trinitro-phenyl) hydrazine (DPPH), tri-2-pyridyl-s-triazine (TPTZ) ( $\geq 99 \%$ ), dimethyl sulfoxide (DMSO) ( $\geq 99 \%)$, phosphate buffer, mushroom tyrosinase, 3,4-dihydroxy-L-phenylalanine (L-DOPA) $(\geq 98 \%$ ), and kojic acid were purchased from Sigma (Sigma Aldrich Chemie GmbH, Schnelldorf, Germany). Folin-Ciocâlteu reagent, hydrochloric acid (37\%), acetone, ethanol, and methanol were purchased from Merck (Darmstadt, Germany). Aluminum chloride $(\geq 98 \%)$ was purchased from Carl Roth (Karlsruhe, Germany). All reagents were of analytical grade and all solvents were of LC grade. Water was of Milli-Q-quality.

\subsection{Sample preparation}

Fresh fruits were collected manually from different locations situated in Cluj County, Romania and Abruzzo province, Italy. The samples were stored in a refrigerator at about $+5{ }^{\circ} \mathrm{C}$ to 
prevent further damage. The unripe and burst fruits were manually separated. Plants were identified, and voucher specimens were deposited in the Herbarium of the Botany Department, Faculty of Pharmacy, "Iuliu Hațieganu” University of Medicine and Pharmacy, Cluj-Napoca.

\subsection{Drying procedure}

Firstly, in order to gain some knowledge about the potential critical quality attributes of the products and critical process parameters, some preliminary experiments were performed (data not shown), allowing the establishment of a reliable drying strategy. Furthermore, in order to study the processes and to define the optimal drying parameters, the design of experiments was developed and analysed using the MODDE Pro 11.0 software (Sartorius Stedim, Sweden).

Three different temperature levels $\left(50,60\right.$, and $\left.70{ }^{\circ} \mathrm{C}\right)$ were used and an oven dryer (Excalibur food dehydrator) was operated parallel to the drying surface of the sample. The dryer was installed in an environment with a relative air humidity of about $40-50 \%$ and an ambient air temperature of about 16-22 ${ }^{\circ} \mathrm{C}$. The dryer is equipped with an automatic temperature controller which sets the air flow temperature with a good accuracy $\left( \pm 0.1^{\circ} \mathrm{C}\right)$. The weight change was recorded using a digital balance with a sensitivity of $0.01 \mathrm{~g}$ (Adam PW254) at 4, $8,12,18,24,36$, and 48 hours during drying. Before beginning the experiments, the dryer system was started in order to achieve a desirable steady state condition. A $5 \mathrm{~g}$ sample of fruits was weighed and spread evenly on a perforated tray, which was suspended inside the preheated laboratory oven.

\subsection{Extraction procedure}

For the extraction of bioactive compounds from dried fruits, the following procedure was used: each sample of dried fruits was first ground and homogenized in a laboratory mill (Retsch Grindomix GM200). The obtained powder was mixed with $50 \mathrm{~mL}$ of $70 \%(\mathrm{v} / \mathrm{v})$ ethanol and homogenized using a laboratory vortex device (Velp Scientifica Classic). The mixture was ultrasonicated for $30 \mathrm{~min}$ in a water bath at $50{ }^{\circ} \mathrm{C}$ and then filtered through a filter paper using a water vacuum filter. The solution was allowed to cool before it was made up to a final volume of $50 \mathrm{~mL}$ with $70 \%$ ethanol.

After the optimal parameters of drying were calculated for each type of fruit, using the method described previously, the frozen fruits were allowed to heat up to room temperature. Consequently, the fruits were dried under the optimized conditions, and the whole process was repeated, as described above, for fresh fruits. The extracts from the $50 \mathrm{~mL}$ flasks were lyophilized. Then, the dry weight extract was resolubilized in $70 \%$ EtOH for antioxidant and total bioactive compound determination, and in aqueous medium with 5\% DMSO for the enzymatic assays.

\subsection{Quantitative determination of total bioactive compounds (total phenolic content (TPC) and total flavonoid content (TFC))}

The total phenolic content (TPC) of the raw extracts was determined using the Folin-Ciocâlteu method as previously described by Mocan, Schafberg, Crisan, \& Rohn (2016). ${ }^{13}$ In a 96 well plate, $20 \mu \mathrm{L}$ of each sample were mixed with $100 \mu \mathrm{L}$ of Folin-Ciocâlteu reagent (diluted 1:10 with distilled water). After $3 \mathrm{~min}, 80 \mu \mathrm{L}$ of sodium carbonate solution $(7.5 \% \mathrm{w} / \mathrm{v})$ were added to the wells. The plate was incubated for $30 \mathrm{~min}$ in the dark at room temperature. A SPECTROstar Nano microplate reader (BMG Labtech, Offenburg, Germany) with 96 well plates was used to measure the absorbance at $760 \mathrm{~nm}$ against a solvent blank. As a reference standard, gallic acid was used. The content of phenolic compounds in raw fruit extracts was expressed as milligrams gallic acid equivalents (GAE) per gram dry weight of raw fruit (mg GAE per $g$ dw fruit). After lyophilization, the optimized extracts were also evaluated in terms of total phenolic content and the results were expressed as milligrams gallic acid equivalents (GAE) per gram dry weight of lyophilized extract (mg GAE per $\mathrm{g}$ dw lyophilized extract).

The total flavonoid content (TFC) of the crude extracts was determined according to the method previously described by Mocan et al. (2017). ${ }^{14} 100 \mu \mathrm{L}$ of $2 \% \mathrm{AlCl}_{3}$ aqueous solution were added to $100 \mu \mathrm{L}$ of sample in a 96 well plate. The plate was incubated at room temperature in the dark for $15 \mathrm{~min}$. The absorbance was measured against a solvent blank at $420 \mathrm{~nm}$ using a SPECTROstar Nano microplate reader (BMG Labtech, Offenburg, Germany) with 96 well plates. The content of flavonoids in raw fruit extracts was expressed as quercetin equivalents $(\mathrm{QE})$ per gram of dry weight (dw) of raw fruits $(\mathrm{mg}$ QE per g dw). After lyophilization, the optimized extracts were evaluated again in terms of total flavonoid content and the results were expressed as milligrams gallic acid equivalents (QE) per gram of dry weight of lyophilized extract (mg QE per g dw lyophilized extract).

\subsection{Analysis of phenolic compounds}

The phenolic profile was determined by LC-DAD-ESI/MS ${ }^{n}$ (Dionex Ultimate 3000 UPLC, Thermo Scientific, San Jose, CA, USA). The phenolic compounds were separated and identified as previously described by Bessada et al. ${ }^{15}$ The obtained extracts were re-dissolved in an ethanol:water $(80: 20, \mathrm{v} / \mathrm{v})$ mixture at a concentration of $50 \mathrm{mg} / \mathrm{mL}^{-1}$. A double online detection was performed using a DAD (280, 330 and $370 \mathrm{~nm}$ as preferred wavelengths) and a mass spectrometer (MS). The MS detection was performed in negative mode, using a Linear Ion Trap LTQ XL mass spectrometer (Thermo Finnigan, San Jose, CA, USA) equipped with an ESI source.

The identification of phenolic compounds was performed based on their chromatographic behaviour and UV-vis and mass spectra by comparison with the standard compounds, when available, and the data reported in the literature giving a tentative identification. Data acquisition was carried out with an Xcalibur® data system (Thermo Finnigan, San Jose, CA, USA). For quantitative analysis, a calibration curve for each available phenolic standard was constructed based on the UVvis signal. For the identified phenolic compounds for which a commercial standard was not available, the quantification was performed through the calibration curve of the most similar 
available standard. The results were expressed as mg per $\mathrm{g}$ of extract.

\subsection{Antioxidant activity assays}

The antiradical activity of the extracts was determined using some broadly used methods: DPPH radical scavenging activity, ABTS radical cation scavenging activity (TEAC), and FRAP (ferric-reducing antioxidant power). Moreover, the inhibition of lipid peroxidation by decreasing thiobarbituric acid reactive substances (TBARS), and the oxidative hemolysis inhibition assay (OxHLIA) were also applied.

2.7.1 DPPH radical scavenging activity. The capacity to scavenge the free radical DPPH was assessed according to the method described by ref. 16 with slight modifications. The mixture in each of the 96-wells consisted of $30 \mu \mathrm{L}$ of sample solution (in a proper dilution) and a $0.004 \% \mathrm{MeOH}$ solution of DPPH. The mixture was incubated for $30 \mathrm{~min}$ in the dark. Finally, the reduction of the DPPH radical was determined by measuring the absorption of the sample at $515 \mathrm{~nm}$. The antioxidant activity according to the DPPH radical scavenging assay was expressed as trolox equivalents (TE) per gram of dry weight of raw fruit (mg TE per $\mathrm{g}$ dw fruit). After lyophilization, the optimized extracts were evaluated again in terms of total flavonoid content and the results were expressed as trolox equivalents (TE) per gram of dry weight of lyophilized extract (mg TE per $\mathrm{g}$ dw lyophilized extract).

2.7.2 TEAC (trolox equivalent antioxidant capacity). Another well-known method to assess the antiradical activity of the plant extracts is the trolox equivalent antioxidant capacity (TEAC) assay, as described previously by Mocan et $a l .{ }^{17}$ The ability of the extracts with antioxidant features to scavenge the $\mathrm{ABTS}^{+}$radicals is compared to the activity of trolox, a vitamin $\mathrm{E}$ analogue. The antioxidant activity according to the TEAC assay was expressed as trolox equivalents (TE) per gram of dry weight of raw fruit (mg TE per $g$ dw fruit). After lyophilization, the optimized extracts were evaluated again in terms of total flavonoid content and the results were expressed as trolox equivalents (TE) per gram of dry weight of lyophilized extract (mg TE per $\mathrm{g}$ dw lyophilized extract).

2.7.3 FRAP (ferric reducing antioxidant power). The FRAP assay was carried out as described by Mocan et al. ${ }^{18}$ with slight modifications. The diluted extracts were added to premixed FRAP reagent containing acetate buffer $(0.3 \mathrm{M}, \mathrm{pH} 3.6)$, tri-2pyridyl-s-triazine (TPTZ) $(10 \mathrm{mM})$ in $40 \mathrm{mM} \mathrm{HCl}$ and ferric chloride $(20 \mathrm{mM})$ in the ratio of $10: 1: 1(\mathrm{v}: \mathrm{v}: \mathrm{v})$. After a 30 min incubation at room temperature, the sample absorbance was read at $593 \mathrm{~nm}$. The antioxidant activity according to the FRAP assay was expressed as trolox equivalents (TE) per gram of dry weight of raw fruit (mg TE per $g$ dw fruit). After lyophilization, the optimized extracts were evaluated again in terms of total flavonoid content and the results were expressed as trolox equivalents (TE) per gram of dry weight of lyophilized extract (mg TE per $\mathrm{g}$ dw lyophilized extract).

2.7.4 TBARS assay. For the TBARS assay, the extracts were re-dissolved in an ethanol : water mixture $(80: 20, \mathrm{v} / \mathrm{v})$ at a concentration of $5 \mathrm{mg} \mathrm{mL} \mathrm{m}^{-1}$. The stock solutions were subjected to eight successive dilutions for analysis. The antioxidant capacity was measured by the decrease of thiobarbituric acid reactive substances (TBARS) using porcine (Sus scrofa) brain homogenates. The colour intensity of malondialdehyde-thiobarbituric acid (MDA-TBA) was measured by its absorbance at $532 \mathrm{~nm}$, following a previously described procedure. ${ }^{19}$ The results were expressed as $\mathrm{EC}_{50}$ values $\left(\mu \mathrm{g} \mathrm{mL}^{-1}\right)$, representing the extract concentration required to inhibit $50 \%$ of the lipid peroxidation. Trolox was used as a positive control.

2.7.5 OxHLIA assay. For the OxHLIA assay, a known mass of extract $(100 \mathrm{mg}$ ) was dissolved in PBS, obtaining different solutions with concentrations ranging from 12.5 to $125 \mu \mathrm{g}$ $\mathrm{mL}^{-1}$. To determine the capacity to inhibit the oxidative hemolysis associated with each of the tested extracts, an ovine erythrocyte solution was used. ${ }^{20}$ The extract concentration able to promote a $\Delta t$ hemolysis delay of $60 \mathrm{~min}$ was calculated based on the $\mathrm{Ht}_{50}$ values of the haemolytic curves of the extracts with different concentrations. ${ }^{21}$

The results were expressed as $\mathrm{EC}_{50}$ values $\left(\mu \mathrm{g} \mathrm{mL}^{-1}\right)$, representing the extract concentration required to keep $50 \%$ of the erythrocyte population intact for $60 \mathrm{~min}$. Trolox was used as a positive control.

\subsection{Cytotoxic activity}

The extracts were re-dissolved in water at $8 \mathrm{mg} \mathrm{mL} \mathrm{m}^{-1}$ concentration and further diluted in the range of 400 to $6.25 \mu \mathrm{g}$ $\mathrm{mL}^{-1}$. The cytotoxic properties were evaluated using four human tumor cell lines: MCF-7 (breast adenocarcinoma), NCI-H460 (non-small cell lung cancer), HeLa (cervical carcinoma), and HepG2 (hepatocellular carcinoma). A non-tumor cell line (PLP2) was also evaluated using a procedure previously described by Abreu et al. (2011). ${ }^{22}$ The sulforhodamine B assay was carried out by Barros et al. (2013), ${ }^{23}$ with ellipticine being used as a positive control and each suspension of cells as a negative control. The results were expressed as $\mathrm{GI}_{50}$ values (the sample concentration that inhibited $50 \%$ of the cell proliferation).

\subsection{Anti-inflammatory activity}

The extracts were re-dissolved in water at a concentration of $8 \mathrm{mg} \mathrm{mL} \mathrm{m}^{-1}$ and then diluted in the range of 400 to $6.25 \mu \mathrm{g}$ $\mathrm{mL}^{-1}$. A mouse macrophage-like cell line RAW 264.7 was used in this study and a Griess reagent system (GRS) kit was used to determine nitric oxide, measured at $515 \mathrm{~nm}$ (ELx800 microplate reader, Bio-Tek Instruments, Inc; Winooski, VT, USA), as described previously. ${ }^{19}$ The results were expressed as $\mathrm{IC}_{50}$ values (the sample concentration providing $50 \%$ of inhibition of NO production) and dexamethasone was used as a positive control, while in negative controls, no LPS was added.

\subsection{Inhibition of fungal $\alpha$-glucosidase}

The inhibition of yeast $\alpha$-glucosidase was assessed by measuring the amount of $p$-nitrophenyl, hydrolyzed by the enzyme from $p$-nitrophenyl- $\alpha$-D-glucopyranoside $(\alpha-p$ NPG). The assay was performed using a previously described methodology with 
some modifications. ${ }^{24} 50 \mu \mathrm{L}$ of extract solutions (sequential dilutions) were mixed with $50 \mu \mathrm{L}$ of the solution of enzyme ( $2 \mathrm{U} \mathrm{mL}^{-1}$ ) in a 96-well plate. The mixture was incubated for 10 minutes at $37{ }^{\circ} \mathrm{C}$ in the dark. Finally, $50 \mu \mathrm{L}$ of $\alpha-p$ NPG solution $(2.5 \mathrm{mM})$ were added to the mixture. All solutions were prepared in phosphate buffer $(0.1 \mathrm{M}, \mathrm{pH}$ 6.8). The mixture was incubated for 10 minutes at $37{ }^{\circ} \mathrm{C}$ in the dark. AGLU control (C) represents $100 \%$ enzyme activity and, in this case, the extract was replaced by phosphate buffer. Sample blanks (D) were also included, for each sample, for correcting the absorbance of the background. For this, buffer was used instead of the substrate. Blank of the control (B) consisted of the buffer (instead of the extract and the substrate) and enzyme. Inhibition (\%) of the AGLU activity was calculated according to the following formula:

$$
\operatorname{Inhibition}(\%)=\frac{(\mathrm{A}-\mathrm{B})-(\mathrm{C}-\mathrm{D})}{(\mathrm{A}-\mathrm{B})} \times 100
$$

where A, B, C, and D are the absorbance values of the control, blank control, sample and blank sample, respectively. The inhibitory activity was expressed as the $\mathrm{IC}_{50}$ value $(\mathrm{mg}$ per $\mathrm{mL}$ $\mathrm{dw}$ lyophilized extract). This value represents the concentration of the extract required to reduce the enzyme activity by $50 \%$ with reference to the control.

\subsection{Rat $\alpha$-glucosidase inhibitory assay}

In this assay, $0.5 \mathrm{~g}$ of rat intestinal acetone powder was dissolved in $10 \mathrm{~mL}$ of phosphate buffer (0.1 M, pH 6.9) and sonicated for $10 \mathrm{~min}$. After centrifugation at $1523 \mathrm{~g}$ for $10 \mathrm{~min}$ at $4{ }^{\circ} \mathrm{C}$, the supernatant was diluted 5 times with phosphate buffer and was used as the enzyme solution. This solution was prepared fresh for each experiment. The measurement of rat AGLU inhibition was performed as described in the previous section.

\subsection{Statistical analysis}

The analyses were performed in triplicate and the obtained results were expressed as mean $\pm \mathrm{SD}$ for each sample. Analysis of variance (ANOVA) was used to determine significant differences between values $(p<0.05)$, followed by multiple comparisons using Tukey's test. The statistical significance of differences between the extracts was evaluated using SPSS 16.0 for Windows (SPSS Inc, Chicago, IL, USA). Statistical correlations between the data were calculated by Pearson's and Spearman's correlation analyses.

\section{Results and discussion}

\subsection{Optimization of the drying process}

The design of experiments was based on a systematic introduction of anticipated variability, which allowed the definition of the relationships between the process factors and their outputs. This was achieved by performing the drying runs following a randomised order and analysing the obtained data. Based on the gained knowledge, the next step was to map the design space, defined as a multidimensional range of input variables, i.e. drying parameters, demonstrated to provide an optimal product.

Firstly, we noticed that an important role in the drying process was played by the temperature of the air flow. This fact is supported by the data provided in Fig. 1 and 2. As the air flow temperature rises, the moisture of the fruits decreases in a shorter time. Secondly, we considered that the effect of temperature is an important factor for preserving the integrity of the bioactive compounds within the plant material. Consequently, to avoid the possibility of further damage to these compounds, we considered that drying at a lower temperature is appropriate. However, the aim of this article being to extrapolate the results on an industrial scale, it is necessary to reduce the time of drying, preserving the quality of the product. Thereby, a compromise between these two factors was made, and an optimal temperature of $60{ }^{\circ} \mathrm{C}$ was considered. The drying parameters were taken into consideration, and the software generated the optimal time of fruit drying at $60^{\circ} \mathrm{C}$.

3.1.1. Optimization of the drying process of Rosa canina pseudofruits. Regarding the Rosa canina pseudofruit drying process, the optimal time of contact with hot air at a temperature of $60{ }^{\circ} \mathrm{C}$, resulting from parameter analysis was 30.4 hours. Erenturk, Gulaboglu, \& Gultekin $(2004)^{25}$ demonstrated in their study that the effect of the air velocity was negligible and the air humidity did not significantly affect the drying of rosehip. Koyuncu, Tosun, \& Ustun $(2003)^{26}$ also studied the influence of the drying air temperature and velocity on the drying time and energy requirement. They concluded that the minimum energy required for drying the rosehips was $6.69 \mathrm{~kW} \mathrm{~h} \mathrm{~kg}^{-1}$ at $70{ }^{\circ} \mathrm{C}$ and $0.5 \mathrm{~m} \mathrm{~s}^{-1}$. This value of the energy requirement is close to that of the rosehips dehydrated at $60{ }^{\circ} \mathrm{C}$ and $0.5 \mathrm{~m} \mathrm{~s}^{-1}$. The browning process was evaluated by measuring the Hunter $L$ parameters of dehydrated rosehips. Interestingly, the best value was obtained for the pseudofruits dried at $60{ }^{\circ} \mathrm{C}$, which is in accordance with the result presented herein. Koca, Ustun, \& Koyuncu $(2009)^{27}$ evaluated the effect of drying conditions on the antioxidant properties of rosehip pseudofruits. They concluded that the best parameters for retention of total phenolics were $50{ }^{\circ} \mathrm{C}$ and $1.5 \mathrm{~m} \mathrm{~s}^{-1}$ air flow rate, and for the retention of total carotenoids the best parameters were $70{ }^{\circ} \mathrm{C}$ and $1.5 \mathrm{~m} \mathrm{~s}^{-1}$. Furthermore, the highest retention of ascorbic acid was obtained at $60{ }^{\circ} \mathrm{C}$ drying temperature and $1.5 \mathrm{~m} \mathrm{~s}^{-1}$ air flow rate.

We also evaluated the influence of the drying air temperature and drying time on the total phenolic content (TPC), total flavonoid content (TFC), and antioxidant activity. The highest content of phenolic compounds was obtained by drying rosehips at $60{ }^{\circ} \mathrm{C}$, as it can be seen in Fig. 3. Regarding the flavonoid content obtained under different drying temperature conditions, the results are inconclusive and cannot be interpreted in order to determine the best condition for the extraction of these compounds (Fig. 3). Interestingly, the antioxidant capacity of the extracts obtained from the pseudofruits dried at $70^{\circ} \mathrm{C}$ was higher than that of those dried at $60{ }^{\circ} \mathrm{C}$ (Fig. 3). 

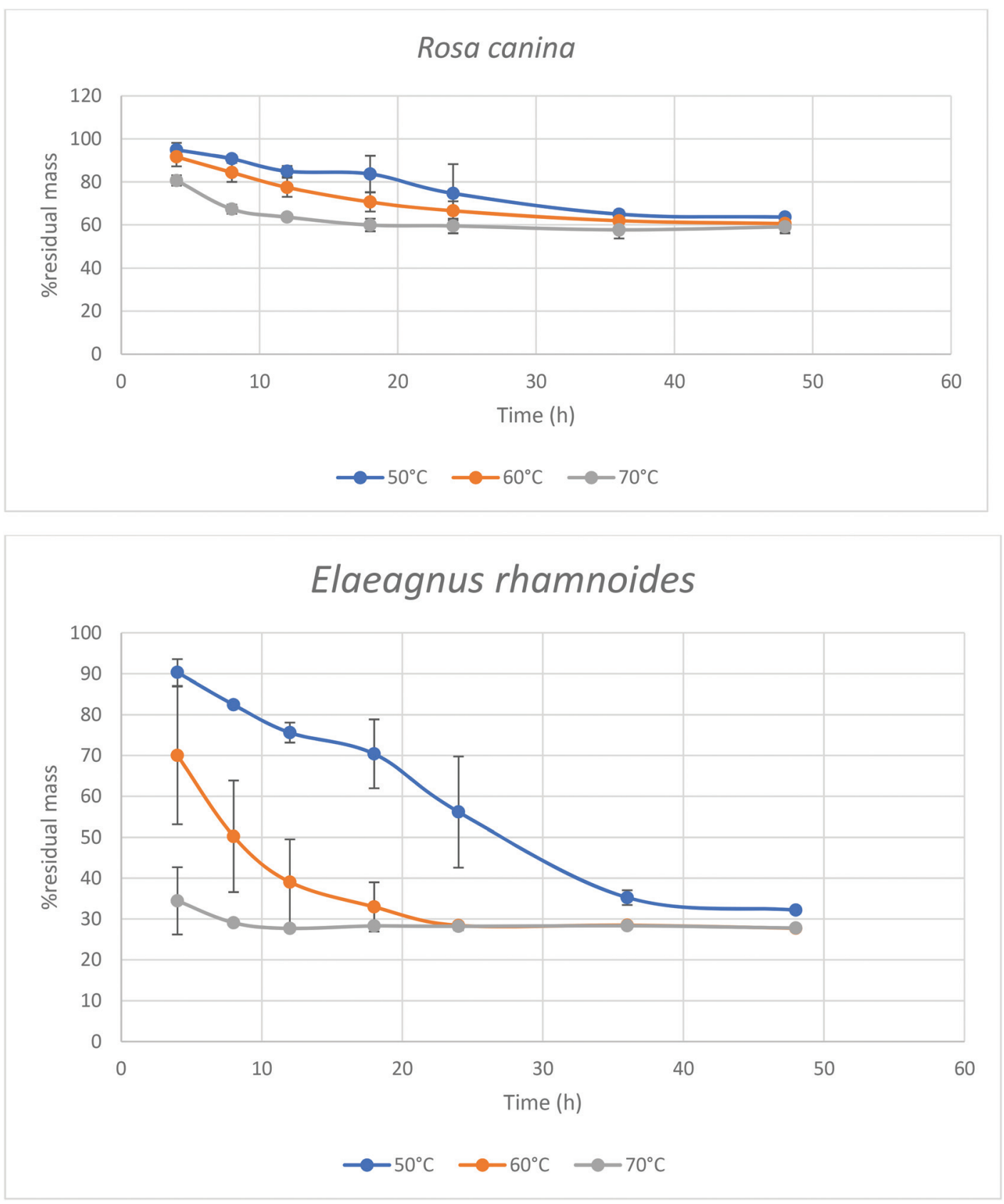

Fig. 1 Percent of residual mass as a function of drying time at temperatures of 50,60 , and $70^{\circ} \mathrm{C}$ for the studied species.

3.1.2. Optimization of the drying process of Elaeagnus rhamnoides fruits. Finally, the optimal time of drying the fruits of Elaeagnus rhamnoides was found to be 24.35 h. ArayaFarias et $a l .{ }^{28}$ studied the impact of temperature on the kinetics of air-drying and freeze-drying of this kind of fruits. They concluded that freeze-drying was found to be a superior method to obtain powders from the fruits of this species, because of the lower residual moisture content, the higher content of nutritional compounds, and the ease of grinding. Gutiérrez et al. ${ }^{29}$ studied the effects of the drying method on the quality and extraction yields of oils from sea buckhorn fruits, and they documented that the drying method did not have a marked effect on the oil quality, but they found that the oils from freeze-dried pulps had a much lower peroxide value, bearing out their enhanced quality.

The effect of the drying temperature on the quality of sea buckhorn was also assessed in this paper. The results showed a higher content of both flavonoid and phenolics in the fruits dried at $70{ }^{\circ} \mathrm{C}$, which could be assigned to the high stability of the compounds in this plant. The antioxidant activity of the extracts obtained from the sea buckhorn fruits dried at $70^{\circ} \mathrm{C}$ was higher than that of those obtained from fruits dried at a lower temperature. Thus, we can conclude that the optimal temperature of drying the sea buckhorn fruits is $70^{\circ} \mathrm{C}$ for $\sim 24 \mathrm{~h}$. 


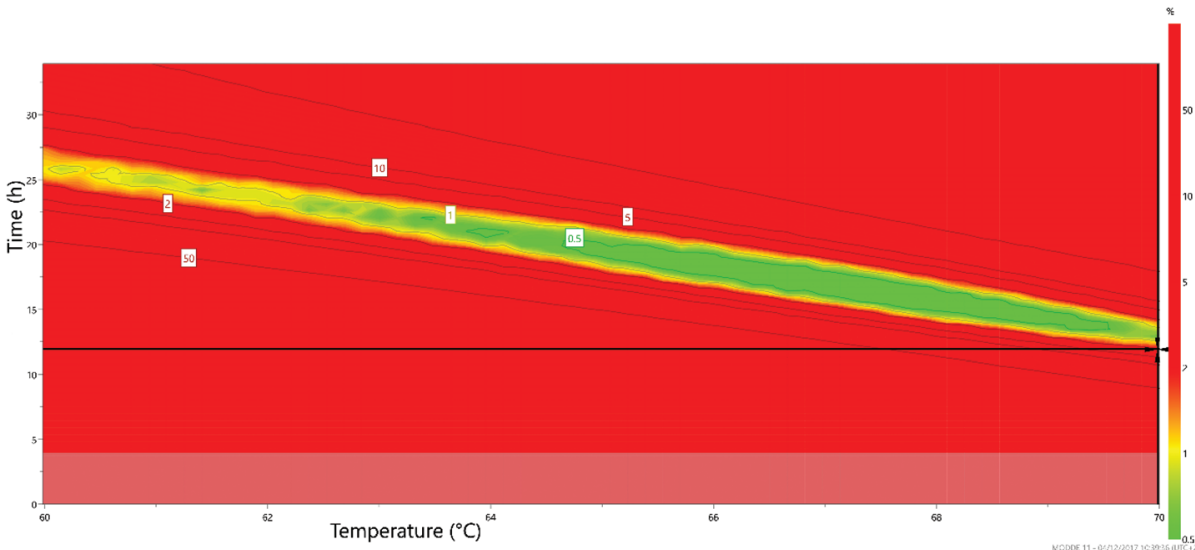

$\mathbf{A}$

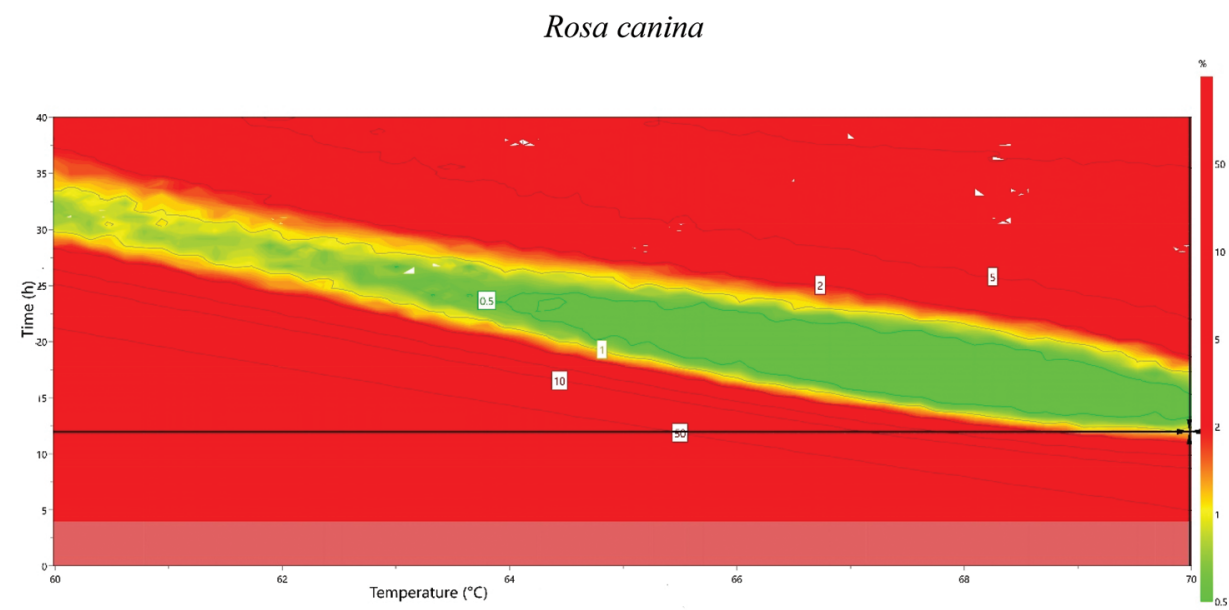

Eleagnus rhamnoides

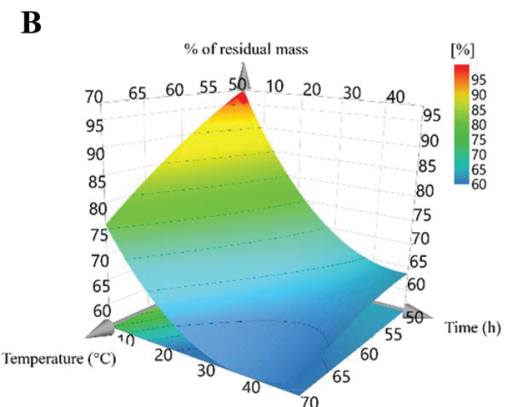

Rosa canina

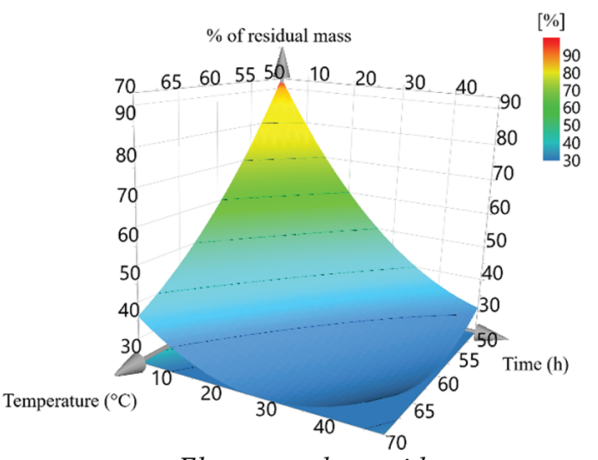

Elaeagnus rhamnoides

Fig. 2 (A) Design spaces representing optimal temperature conditions as a function of time for drying processes, and (B) 3D response surface plots defining the influence of the critical drying process parameters (temperature and time of drying) over the percent of residual mass.

\subsection{Determination of the phenolic compounds of the optimized extracts}

3.2.1 Total phenolic content (TPC). To evaluate the total phenolic content in the fruit extracts, the Folin-Ciocâlteu method was used. Although there are some limitations of this method, such as the interference of vitamin $\mathrm{C}$ content of extracts on the final results, it is extensively used in the scientific literature. ${ }^{30}$

Rosa canina is a species which is known for its phenolic compound rich composition. This is once again proved by the result of our research. The species studied herein presented a value of $24 \pm 1 \mathrm{mg}$ GAE per $\mathrm{g}$ dw rosehip lyophilized extract 


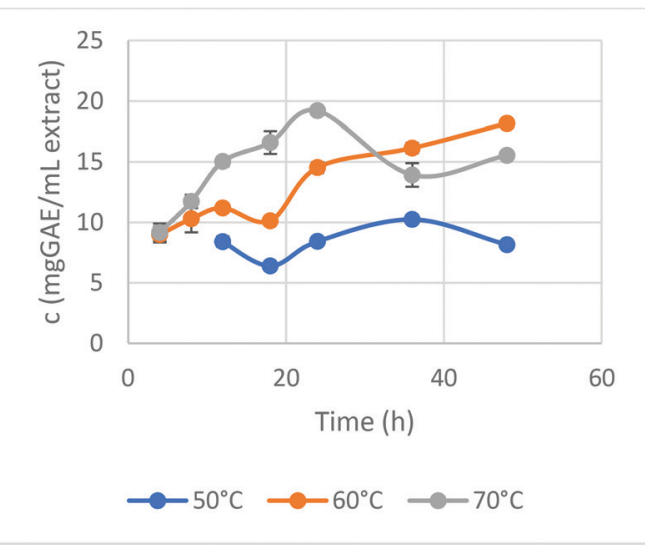

A Total Phenolic Content (TPC)

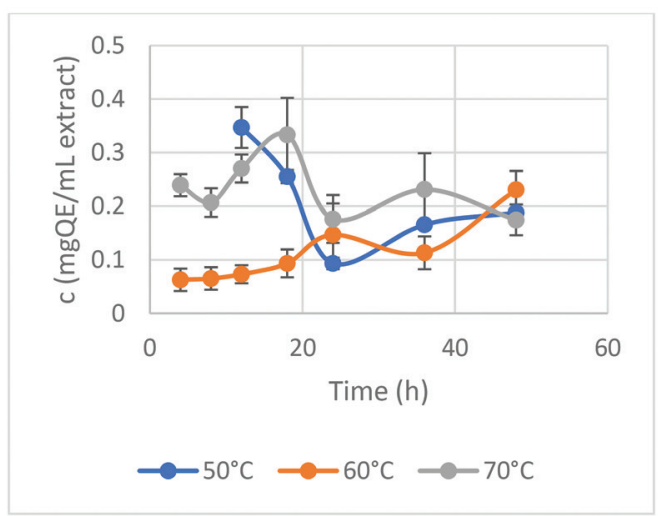

\section{Total Flavonoid Content (TFC)}

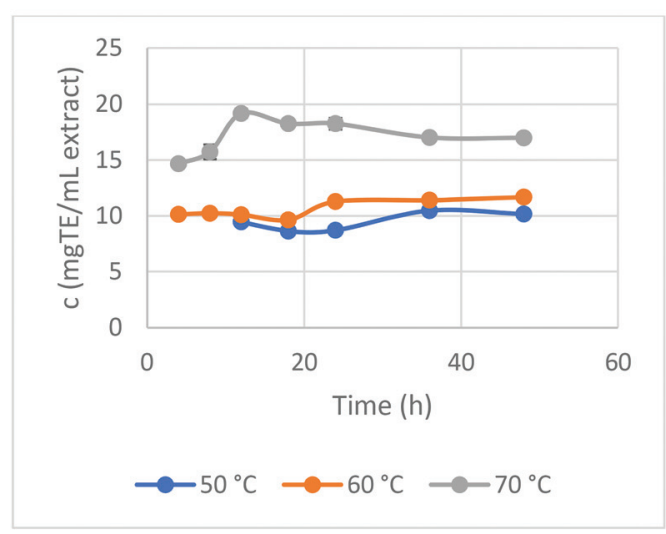

E DPPH radical scavenging activity (DPPH)

Rosa canina

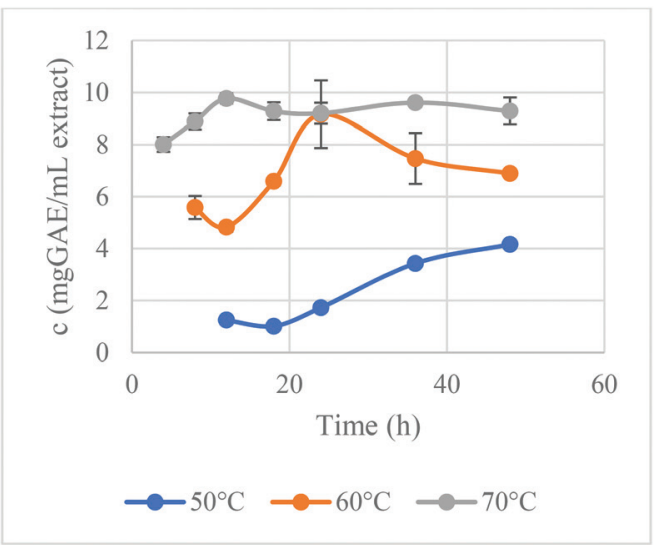

B

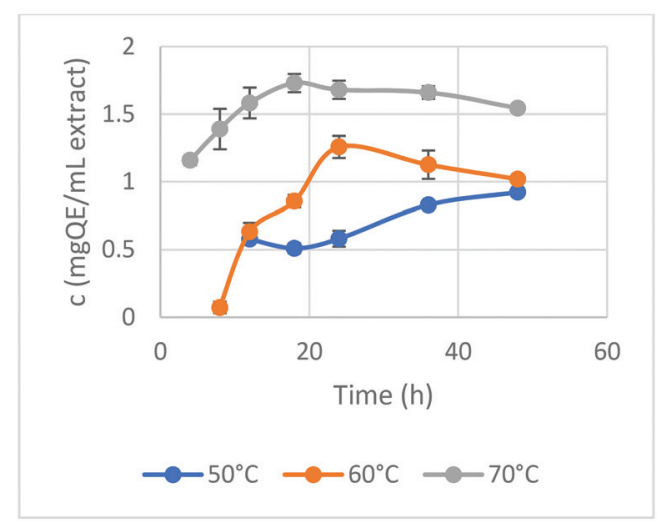

D

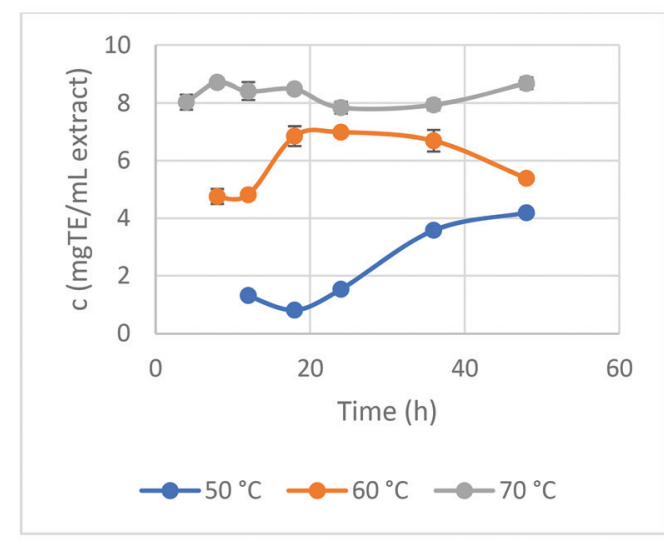

$\mathbf{F}$

Fig. 3 Total phenolic content (TPC), total flavonoid content (TFC), and DPPH radical scavenging activity (DPPH) as a function of time under the temperature conditions of dried plant samples $\left(50,60\right.$, and $\left.70^{\circ} \mathrm{C}\right)$ of Rosa canina $(A, C$ and $E)$ and Elaeagnus rhamnoides $(B, D$ and $F)$.

(Table 2). In a study conducted on different varieties of the Rosa canina species, ${ }^{31}$ it was concluded that the highest content of phenolics was found in Rosa canina var. transitoria f. ramosissima from Agiesel, Bistrița-Năsăud county, România (5.751 $\pm 0.1464 \mathrm{mg}$ GAE per $\mathrm{g}$ frozen pulp). On the other hand, Ercisli et al. found that rosehip pseudofruits collected from
Erzurum, Turkey, showed a value of $96 \mathrm{mg}$ GAE per $\mathrm{g} \mathrm{dw}{ }^{32} \mathrm{~A}$ similar result was documented by a research team from Serbia, which documented a value of $96.2 \pm 4.35 \mathrm{mg}$ GAE per $\mathrm{g}$ of $\mathrm{dw}$ of puree extract, a traditional Serbian preparation. Another study conducted by Montazeri et al. documented a content of $424.6 \pm 1.8 \mathrm{mg}$ GA per $\mathrm{g}$ of methanol extract from Rosa canina 
rosehip without fruits, commercially available from the supplier Martin Bauer, Germany. ${ }^{33}$

The phenolic content of the extracts obtained from the fruits of sea buckthorn was $13.2 \pm 0.6 \mathrm{mg}$ GAE per g of dw lyophilized extract. Compared to the other samples collected from different areas, the dried fruit extract of sea buckhorn showed a comparable content of phenolics. A Czech team reported that the fresh fruits collected from Zabice, Czech Republic, contained 8.62-14.17 mg GAE per $\mathrm{g}$ of fresh fruits. ${ }^{34}$ Another team collected fresh fruits from southern Sweden and concluded that the fruits contained between 1.14 and $2.44 \mathrm{mg}$ GAE per $g$ of fresh fruits. There results suggest that the drying process does not affect the phenolic composition of $E$. rhamnoides fruits, and the process conditions can be applied in industry.

3.2.2. Total flavonoid content (TFC). The aim of this study was to find the best drying conditions for extracting the bioactive compounds from the studied plant materials. In this section, we will compare the results found in the literature regarding the composition of bioactive compounds of the studied part of the plant (in our case, fruits, or pseudofruits) with those obtained by us.

A spectrophotometric assay based on aluminium-complex formation is one of the most commonly used procedures for quantification of TFC in food or medicinal plant samples. Although it was proved that this method did not react uniformly with all the compounds in the flavonoid class, ${ }^{35}$ we considered these results as preliminary, and we further investigated the chemical composition using up-to-date and modern techniques.

The total flavonoid content of the Rosa canina optimized extract was $1.4 \pm 0.1 \mathrm{mg}$ QE per $\mathrm{g} \mathrm{dw}$ (Table 2). This is comparable to the highest value of TFC obtained for Rosa canina var. assiensis from the same location (Cluj-Napoca, România), which was $1.632 \pm 0.0545 \mathrm{mg}$ QE per $\mathrm{g} d \mathrm{~d}$, the value obtained by a different group of researchers. ${ }^{31}$ The higher content of flavonoids can be ascribed to the fact that in their case, the plant material was extracted 3 times, whereas, here, it was extracted just once. Tumbas et al. also documented an extraction procedure of bioactive compounds from Rosa canina pseudofruits collected from Rtanj mountain (Serbia). ${ }^{36}$ They macerated the plant material twice in $500 \mathrm{~mL}$ of acetone at room temperature for $24 \mathrm{~h}$, followed by evaporation to dryness. The highest value of TFC was obtained for the Fr3 fraction, which was $504.69 \mu \mathrm{g}$ per $\mathrm{kg}$ of fresh pseudofruits. In their work, Demir et al. evaluated the total flavonoid content of pseudofruits collected from Gümüșhane, Turkey. ${ }^{37}$ They revealed a value of $9.48 \pm 0.94 \mathrm{mg}$ rutin equivalents per $\mathrm{g} d \mathrm{dw}$. However, a comparison cannot be made between the results due to the different standards used.

Finally, we evaluated the total flavonoid content in E. rhamnoides fruits. The value was $4.5 \pm 0.1 \mathrm{mg}$ QE per $\mathrm{g} \mathrm{dw}$. Rop et al. also evaluated the total flavonoid content in fresh fruits collected from Zabcice, Czech Republic. ${ }^{34}$ The values were expressed in rutin equivalents and ranged between 4.18 and $7.97 \mathrm{~g}$ RE per $\mathrm{kg}$ of fresh material.

We can conclude that the drying conditions are very important in order to preserve the flavonoids in the plant materials.
Moreover, our study demonstrates that the drying procedure, using optimal conditions (e.g. a temperature of $60^{\circ} \mathrm{C}$ ), does not affect the quality of the final products. This fact is proved by the comparable results of flavonoid composition.

3.2.3. HPLC-DAD-ESI/MS identification of phenolic compounds. The chromatographic analyses of the phenolic compound profiles of $R$. canina and E. rhamnoides hydroethanolic extracts are shown in Table 1 and Fig. 5. Both samples contained only $O$-glycosylated flavonoids, eight in $R$. canina (eriodictyol, quercetin, and isorhamnetin derivatives) and ten in E. rhamnoides (quercetin and isorhamnetin derivatives). The peaks $\mathbf{4}^{\mathbf{R}}$ and $\mathbf{4}^{\mathbf{E}}\left([\mathrm{M}-\mathrm{H}]^{-}\right.$at $m / z 463$ and 609 , respectively) were identified as quercetin-3-O-glucoside and quercetin-3-Orutinoside, respectively, by comparing their retention times and UV spectra with the available commercial standards. Two eriodictyol derivatives were identified in the $R$. canina samples, presenting a pseudomolecular ion $[\mathrm{M}-\mathrm{H}]^{-}$at $m / z 449$, being tentatively identified as eriodictyol -O-hexoside (the peaks $\mathbf{1}^{\mathbf{R}}$ and $2^{\mathrm{R}}$ ) following the chromatographic characterization method previously described by Guimarães et al. (2013) in the $R$. canina samples. ${ }^{38}$ Two more quercetin derivatives were also identified (apart from the peaks $4^{\mathrm{R}} / 4^{\mathrm{E}}$ ) in $R$. canina, the peaks $3^{\mathbf{R}}$ and $5^{\mathbf{R}}$, tentatively identified as quercetin-O-rhamnoside $\left([\mathrm{M}-\mathrm{H}]^{-}\right.$at $\mathrm{m} / \mathrm{z} 447)$ and quercetin- $O$-hexoside $\left([\mathrm{M}-\mathrm{H}]^{-}\right.$at $\left.\mathrm{m} / \mathrm{z} 463\right)$, respectively, according to the method described by Guimarães et al. (2013). ${ }^{38}$ Isorhamnetin $O$-glycosylated derivatives were, without a doubt, the most representative phenolic compounds found in both samples. The peaks $6^{\mathrm{R}} / 7^{\mathrm{R}} / \mathbf{8}^{\mathrm{R}}$ and $\mathbf{8}^{\mathrm{E}} / 9^{\mathrm{E}} / \mathbf{1 0}^{\mathrm{E}}$ presented a pseudomolecular ion $[\mathrm{M}-\mathrm{H}]^{-}$at $\mathrm{m} / \mathrm{z} 447$ and 477 , respectively, and a unique $\mathrm{MS}^{2}$ fragment at $m / z 315$ (isorhamnetin aglycone), corresponding to the loss of a pentosyl moiety and a hexosyl moiety, respectively, being for that manner, tentatively identified as isorhamnetin- $O$-pentoside and isorhamnetin-O-hexoside, respectively. The peaks $5^{\mathbf{E}} / \mathbf{6}^{\mathbf{E}} / 7^{\mathbf{E}}$ were tentatively identified as isorhamnetin- $O$-deoxyhexoside- $O$-hexoside, presenting a pseudomolecular ion $[\mathrm{M}-\mathrm{H}]^{-}$at $\mathrm{m} / z 623$ and a unique $\mathrm{MS}^{2}$ fragment at $\mathrm{m} / \mathrm{z} 315$ corresponding to the loss of a rutinosyl moiety (deoxyhexosyl plus a hexosyl moiety). The peaks $\mathbf{2}^{\mathrm{E}} / \mathbf{3}^{\mathrm{E}}$ presented a pseudomolecular ion $[\mathrm{M}-\mathrm{H}]^{-}$at $\mathrm{m} / \mathrm{z}$ 785 , which when compared to the peaks $5^{\mathrm{E}} / \mathbf{6}^{\mathrm{E}} / 7^{\mathrm{E}}$, reveals only the attachment of one more hexosyl group to the molecule, being, for that manner, tentatively identified as isorhamnetin$O$-deoxyhexoside-hexoside-O-hexoside. Finally, the peak $\mathbf{1}^{\mathbf{E}}$ presented a pseudomolecular ion $[\mathrm{M}-\mathrm{H}]^{-}$at $m / z 639$ and two subsequent $\mathrm{MS}^{2}$ fragments at $\mathrm{m} / \mathrm{z} 477$ and $\mathrm{m} / \mathrm{z} 315$, corresponding to the loss of two hexosyl moieties, being tentatively identified as isorhamnetin- $O$-hexoside- $O$-hexoside.

Regarding the quantification eriodictyoleryodictiol $O$-glycosylated derivatives were the most abundant in $R$. canina samples, $0.244 \mathrm{mg} \mathrm{g}^{-1}$ of extract, followed by quercetin-3-Oglucoside $\left(0.172 \mathrm{mg} \mathrm{g}^{-1}\right.$ of extract). These values are in accordance with the ones found by Guimarãeset al. $(2013)^{38}$ also in $R$. canina samples. Turkben et al. also documented a value in the range of $0.00276-0.00520 \mathrm{mg}$ per $\mathrm{g}$ of plant material. ${ }^{39} \mathrm{As}$ previously stated isorhamnetin $O$-glycosylated derivatives represented the majority of the phenolic compounds found in 
Table 1 Retention time $\left(R_{\mathrm{t}}\right)$, wavelength of maximum absorption $\left(\lambda_{\max }\right)$, mass spectral data, tentative identification, and quantification of the phenolic compounds present in the optimized extracts

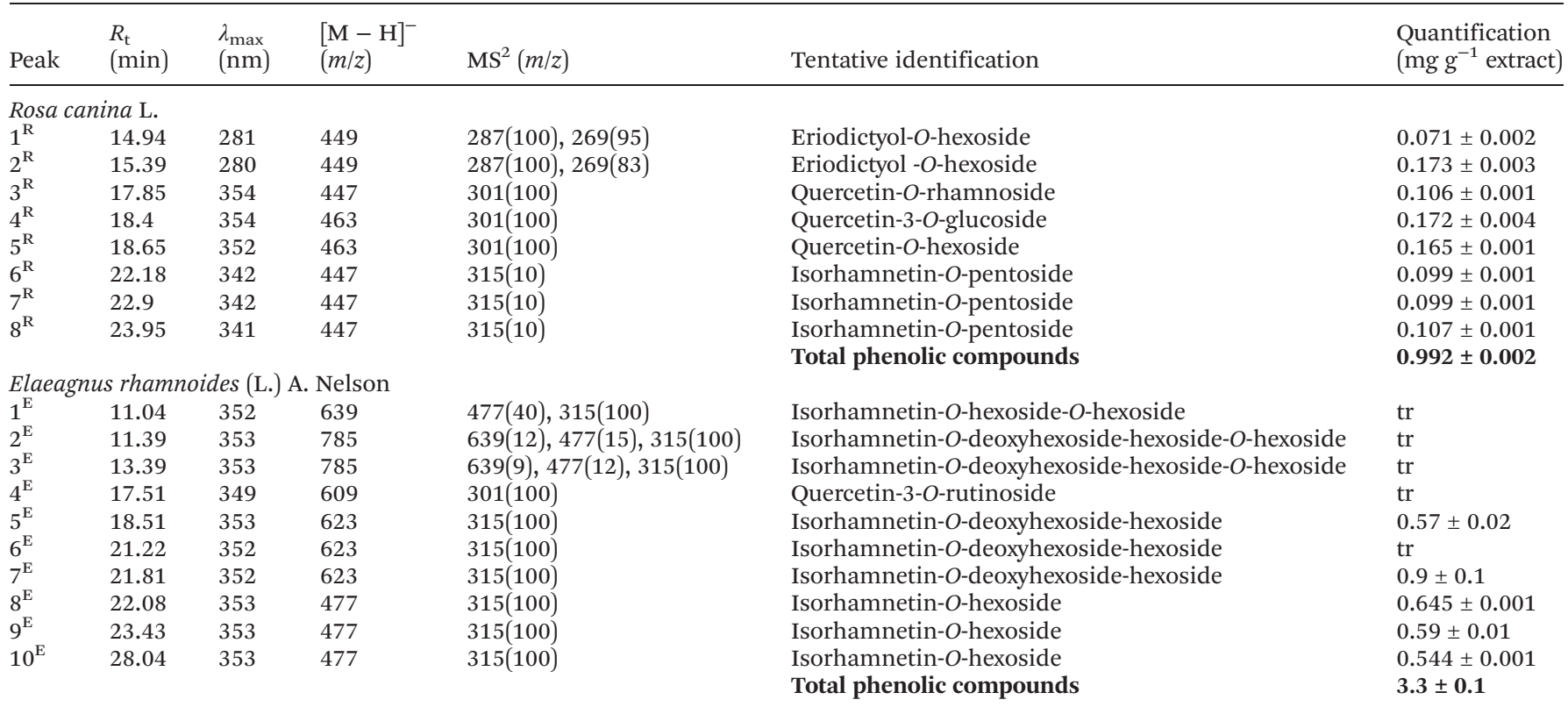

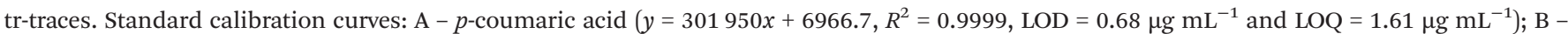
$(+)$-catechin $\left(y=84950 x-23200, R^{2}=1, \mathrm{LOD}=0.44 \mu \mathrm{g} \mathrm{mL}-1\right.$ and LOQ $\left.=1.33 \mu \mathrm{g} \mathrm{mL} \mathrm{mL}^{-1}\right) ; \mathrm{C}-$ quercetin $3-O$-rutinoside $\left(y=13343 x+76751, R^{2}=\right.$ $0.9998, \mathrm{LOD}=0.25 \mu \mathrm{g} \mathrm{mL} \mathrm{m}^{-1}$ and $\left.\mathrm{LOQ}=1.09 \mu \mathrm{g} \mathrm{mL} \mathrm{m}^{-1}\right) ; \mathrm{D}-$ quercetin $3-O$-glucoside $\left(y=34843 x-160173, R^{2}=0.9998, \mathrm{LOD}=0.21 \mu \mathrm{g} \mathrm{mL}-1\right.$ and $\left.\mathrm{LOQ}=0.71 \mu \mathrm{g} \mathrm{mL} \mathrm{mL}^{-1}\right) ; \mathrm{E}-$ apigenin-6-C-glucoside $\left(y=107025 x+61531, R^{2}=0.9989, \mathrm{LOD}=0.19 \mu \mathrm{g} \mathrm{mL} \mathrm{mL}^{-1}\right.$ and LOQ $\left.=0.63 \mu \mathrm{g} \mathrm{mL}^{-1}\right) ; \mathrm{F}-\mathrm{narin}^{-}$ genin $\left(y=18433 x+78903, R^{2}=0.9998, \mathrm{LOD}=0.17 \mu \mathrm{g} \mathrm{mL} \mathrm{L}^{-1}\right.$ and LOQ $\left.=0.81 \mu \mathrm{g} \mathrm{mL}{ }^{-1}\right) ; \mathrm{G}-$ chlorogenic acid $\left(y=168823 x-161172, R^{2}=0.9999\right.$, $\mathrm{LOD}=0.20 \mu \mathrm{g} \mathrm{mL} \mathrm{mL}^{-1}$ and LOQ $=0.68 \mu \mathrm{g} \mathrm{mL}{ }^{-1}$ ). Caffeoyl-2,7-anhydro-3-deoxy-2-octulopyranosonic acids (CDOA).

both samples, especially in the E. rhamnoides fruit extracts, representing all of the total phenolic compounds quantified in this sample (3.3. $\mathrm{mg} \mathrm{g}^{-1}$ of extract). This bioactive compound can act as a tyrosinase inhibitor and as an anticoagulant. Moreover, it was proved that the compound can be used as a cytotoxic agent against BEL-7402 hepatocellular carcinoma cells. ${ }^{40}$ Although the data show a high content of this compound in the studied extract, it seems that the same extract exerted no detectable cytotoxic effect on different cell lines (Table 3). This contradictory result can be explained by the fact that the flavone is mostly glycosylated, and in this form, it cannot diffuse through the cell membrane, thus, the activity cannot be detected. Further in vivo studies are required to assess the cytotoxic activity of isorhamnetin and the bioavailability of its glycosylated derivatives.

\subsection{Antioxidant activity}

The in vitro evaluation of the antioxidant capacity of plant extracts is useful in order to determine the quantity of bioactive compounds. Moreover, the in vivo antioxidant activity can be an indicator of various in vivo potential applications. In this study, the antioxidant capacity was evaluated using five different methods, in order to identify the antioxidant mechanism: DPPH radical scavenging, TEAC (trolox equivalent antioxidant capacity), FRAP (ferric reducing antioxidant power), TBARS (thiobarbituric acid reactive substances), and OxHLIA (oxidative hemolysis inhibition assay). A summary of the antioxidant capacities of the studied extracts is presented in Table 2 .

Regarding the Rosa canina pseudofruit extract, the inhibitory activity of DPPH radicals was $29 \pm 1 \mathrm{mg}$ TE per $\mathrm{g}$ dw lyophilized extract. Roman et al. also assessed this parameter for several varieties and the subspecies of Rosa canina from the Romanian territory. The highest value of antioxidant power was exhibited by Rosa canina var. transitoria f. ramosissima (Bistrita-Nasaud, Agiesel), and it was $127.8 \pm 1.41 \mu \mathrm{M}$ trolox/ $100 \mathrm{~g}$ pulp. ${ }^{31}$ The capacity of rosehip extracts to neutralize the ABTS cation radical was also assessed, and it was $14.6 \pm 0.3 \mathrm{mg}$ TE per $g$ dw lyophilized extract. Demir et al. also assessed this parameter and found that the rosehip extracts collected from the Gümüşhane region of Turkey exhibited a value of $35.51 \mathrm{mmol}$ TE per $\mathrm{g}$ dry weight in terms of ABTS scavenging. ${ }^{37}$ Interestingly, the highest value of antioxidant power was exhibited by the FRAP assay, suggesting that this can be one of the main antioxidant mechanisms. The studied Rosa canina pseudofruits exhibited a value of $98.612 \pm 3.127 \mathrm{mg}$ TE per $\mathrm{g}$ dw. This parameter was also assessed for the pseudofruits collected from the Republic of Serbia, and it was found to be $88.2 \pm 1.99 \mathrm{mg}$ AAE per $\mathrm{g} \mathrm{dw}{ }^{41}$ Unfortunately, the results could not be compared because of the different means of results expression. Regarding the results obtained for the TBARS and OxHLIA assays, the $\mathrm{IC}_{50}$ values were $117 \pm 4$ and 
Table 2 Total phenolic content, total flavonoid content and antioxidant activity of the optimized extracts

\begin{tabular}{|c|c|c|}
\hline & Rosa canina & Elaeagnus rhamnoides \\
\hline TPC (mg GAE per g dw) & $24 \pm 1$ & $13.2 \pm 0.6$ \\
\hline TFC (mg QE per g dw) & $1.4 \pm 0.1$ & $4.5 \pm 0.1$ \\
\hline DPPH (mg TE per $g$ dw) & $29 \pm 1$ & $12.5 \pm 0.6$ \\
\hline TEAC (mg TE per g dw) & $14.6 \pm 0.3$ & $5.9 \pm 0.2$ \\
\hline FRAP (mg TE per g dw) & $99 \pm 3$ & $41.9 \pm 0.8$ \\
\hline TBARS $\left(\mathrm{IC}_{50} ; \mu \mathrm{g} \mathrm{mL}^{-1}\right)^{a}$ & $117 \pm 4$ & $91 \pm 1$ \\
\hline $\begin{array}{l}\text { OxHLIA } \Delta t=60 \mathrm{~min} \\
\left(\mathrm{IC}_{50} ; \mu \mathrm{g} \mathrm{mL} \mathrm{mL}^{-1}\right)^{a}\end{array}$ & $309 \pm 17$ & $331 \pm 17$ \\
\hline
\end{tabular}

$309 \pm 17 \mu \mathrm{g} \mathrm{mL}^{-1}$, respectively. Regarding the TBARS assay result, an $\mathrm{IC}_{50}$ value of $87.20 \pm 2.17 \mu \mathrm{g} \mathrm{mL} \mathrm{m}^{-1}$ was previously reported for a hydroethanolic extract, which is lower than the one obtained herein but can be possibly explained by the different extraction method applied (maceration with 50\% ethanol, v/v). ${ }^{42}$ In terms of anti-hemolytic capacity, it was not possible to compare the results obtained in the present study with previous results since it is, to the best of our knowledge, the first time that it was assessed.

Hippophae rhamnoides fruits exhibited a lower antioxidant capacity compared to Rosa canina pseudofruits. Thus, the DPPH scavenging activity was $12.5 \pm 0.6 \mathrm{mg}$ TE per $\mathrm{g}$ dw lyophilized extract. This value is similar to those obtained by Sharma et al. for the fruits collected from India and extracted using different methods. The highest value obtained was 28.40 $\pm 0.19 \mathrm{mg}$ TE per $\mathrm{g}$ dw extract using microwave-assisted extraction, and the lowest was obtained for macerated fruits, which was $14.28 \pm 0.31 \mathrm{mg}$ TE per $\mathrm{g} .{ }^{43}$ Regarding the ABTS radical scavenging assay, the result $(5.9 \pm 0.2 \mathrm{mg}$ TE per $\mathrm{g}$ dw lyophilized extract) was similar to that obtained by Gao et al. for the ascorbate-free extracts (4.16-7.02 $\mu \mathrm{mol}$ TE per g). ${ }^{5}$ The FRAP value of the studied fruit extract was higher than the other assays performed and was $41.9 \pm 0.8 \mathrm{mg}$ TE per $\mathrm{g}$ dw. It is possible that the extracts exert an important antioxidant activity through this mechanism. Korekar et al. also documented a high antioxidant activity through this assay, reporting that the fruits collected from India exhibited values of 7.50-14.57 mM $\mathrm{FeSO}_{4}$. The $\mathrm{IC}_{50}$ values obtained for the TBARS and OxHLIA assays were $91 \pm 1$ and $331 \pm 17 \mu \mathrm{g} \mathrm{mL}{ }^{-1}$, respectively. The comparison of these results with previous ones was not possible given the scarcity of studies applying these assays to these fruit extracts.

\subsection{Cytotoxic and anti-inflammatory activities}

The evaluation of the cytotoxic activity of the extracts was performed on malignant and normal cell lines. The results are presented in Table 3 and are in concordance with those from various studies performed in the last decades. The extracts did not present any cytotoxic activity neither on cancerous nor on
Table 3 Cytotoxic, anti-inflammatory and inhibitory activities of the optimized extracts against fungal and mammalian $\alpha$-glucosidase

\begin{tabular}{|c|c|c|}
\hline & $\begin{array}{l}\text { Rosa } \\
\text { canina }\end{array}$ & $\begin{array}{l}\text { Elaeagnus } \\
\text { rhamnoides }\end{array}$ \\
\hline \multicolumn{3}{|l|}{ Cytotoxic activity $^{a}\left(G I_{50} ; \mu g L^{-1}\right)$} \\
\hline NCI H460 (non-small cell lung cancer) & $>400$ & $>400$ \\
\hline MCF-7 (breast carcinoma) & $>400$ & $>400$ \\
\hline HepG2 (hepatocellular carcinoma) & $>400$ & $>400$ \\
\hline HeLa (cervical carcinoma) & $>400$ & $>400$ \\
\hline PLP2 (porcine liver primary culture) & $>400$ & $>400$ \\
\hline \multicolumn{3}{|l|}{ Anti-inflammatory activity ${ }^{b}\left(I_{50} ; \mu g m L^{-1}\right)$} \\
\hline NOS production & $>400$ & $>400$ \\
\hline \multicolumn{3}{|l|}{ Inhibitory capacity of $\alpha$-glucosidase } \\
\hline Fungal $\left(\mathrm{IC}_{50} ; \mathrm{mg} \mathrm{mL}^{-1}\right)$ & $0.54 \pm 0.03$ & $3.1 \pm 0.2$ \\
\hline Mammalian $\left(\% I ; 8 \mathrm{mg} \mathrm{mL}^{-1}\right)$ & $15 \pm 6$ & $28 \pm 4$ \\
\hline \multicolumn{3}{|c|}{$\begin{array}{l}{ }^{a} \mathrm{GI}_{50} \text { values for ellipticine: } 1.03 \pm 0.09 \mu \mathrm{g} \mathrm{mL} \mathrm{mL}^{-1}(\mathrm{NCI}-\mathrm{H} 460), 0.91 \pm \\
0.04 \mu \mathrm{g} \mathrm{mL} \mathrm{L}^{-1}(\mathrm{MCF}-7), 1.1 \pm 0.2 \mu \mathrm{g} \mathrm{mL} \mathrm{mL}^{-1}(\mathrm{HepG}), 1.91 \pm 0.06 \mu \mathrm{g} \mathrm{mL} \\
\text { (HeLa), and } 3.2 \pm 0.7 \mu \mathrm{g} \mathrm{mL}^{-1} \text { (PLP2). }{ }^{b} \mathrm{IC}_{50} \text { for dexamethaxone: } 16 \pm \\
1 \mu \mathrm{g} \mathrm{mL} \mathrm{mL}^{-1} \text { (NOS). Different letters in the same row mean significant } \\
\text { differences }(p<0.05) \text {. }\end{array}$} \\
\hline
\end{tabular}

normal cell lines. Although it was demonstrated that isorhamnetin, a flavonol extracted from the E. rhamnoides species can exert a cytotoxic activity against BEL-7402 hepatocellular carcinoma cells, the quantity of this compound in the extract is very low, thus, the cytotoxic activity is not detectable. ${ }^{40}$

The anti-inflammatory activity of the studied extracts was not detected, although some previous studies regarding the Rosa canina pseudofruit extract have demonstrated that it can reduce the chemotaxis of peripheral blood PMNs. ${ }^{44}$

3.4.1. Inhibition of fungal and mammalian $\alpha$-glucosidase. Small intestinal $\alpha$-glucosidase is a key enzyme for dietary carbohydrate digestion in humans. Inhibitors of this enzyme may be effective in retarding carbohydrate digestion and glucose absorption to suppress postprandial hyperglycemia. Some naturally-occurring compounds from various plants are known to inhibit this enzyme, thus, it is of a great importance to assess the enzyme inhibitory activity. The data regarding the $\alpha$-glucosidase inhibitory activity of the studied extracts are presented in Table 3. Also, the logarithm of extract concentration $\left(\mathrm{mg} \mathrm{mL}^{-1}\right)$, plotted as a function of $\% I$ (percent of enzyme inhibition) is presented in Fig. 4.

The beneficial effects of Rosa canina pseudofruit preparations on diabetes prevention is known in traditional medicine. Various studies were conducted in order to establish the mechanism of action involved. It was found in 2016 by Taghizadeh et al. that the extract of rosehips can exert antihyperglycemic and antihyperlipidemic effects in streptozocininduced diabetic rats. ${ }^{45}$ Moreover, in 2017 Fattanhi et al. documented that the extract from Rosa canina pseudofruits can act as a growth factor in pancreatic $\beta$-cell lines. The beneficial effects of the extracts obtained from rosehips have been demonstrated in a clinical trial from 2015. It was proved that the extract can reduce fasting blood glucose and total chole- 


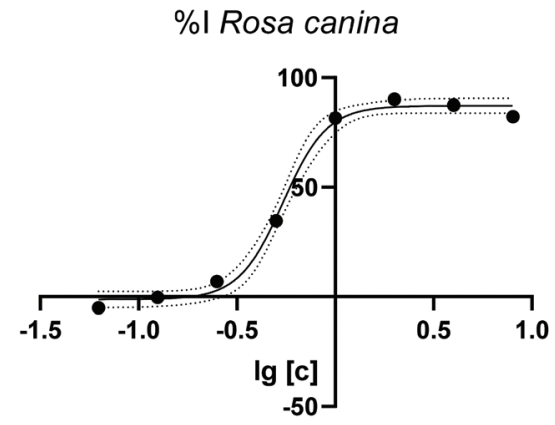

\% Elaeagnus rhamnoides

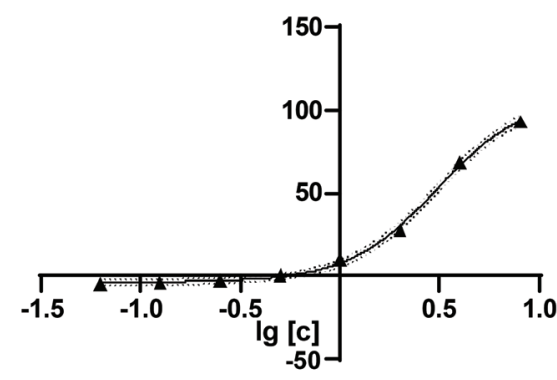

Fig. 4 Graphical representation of logarithm of extract concentration (log[c]) as a function of percent of enzyme inhibition (\%/).

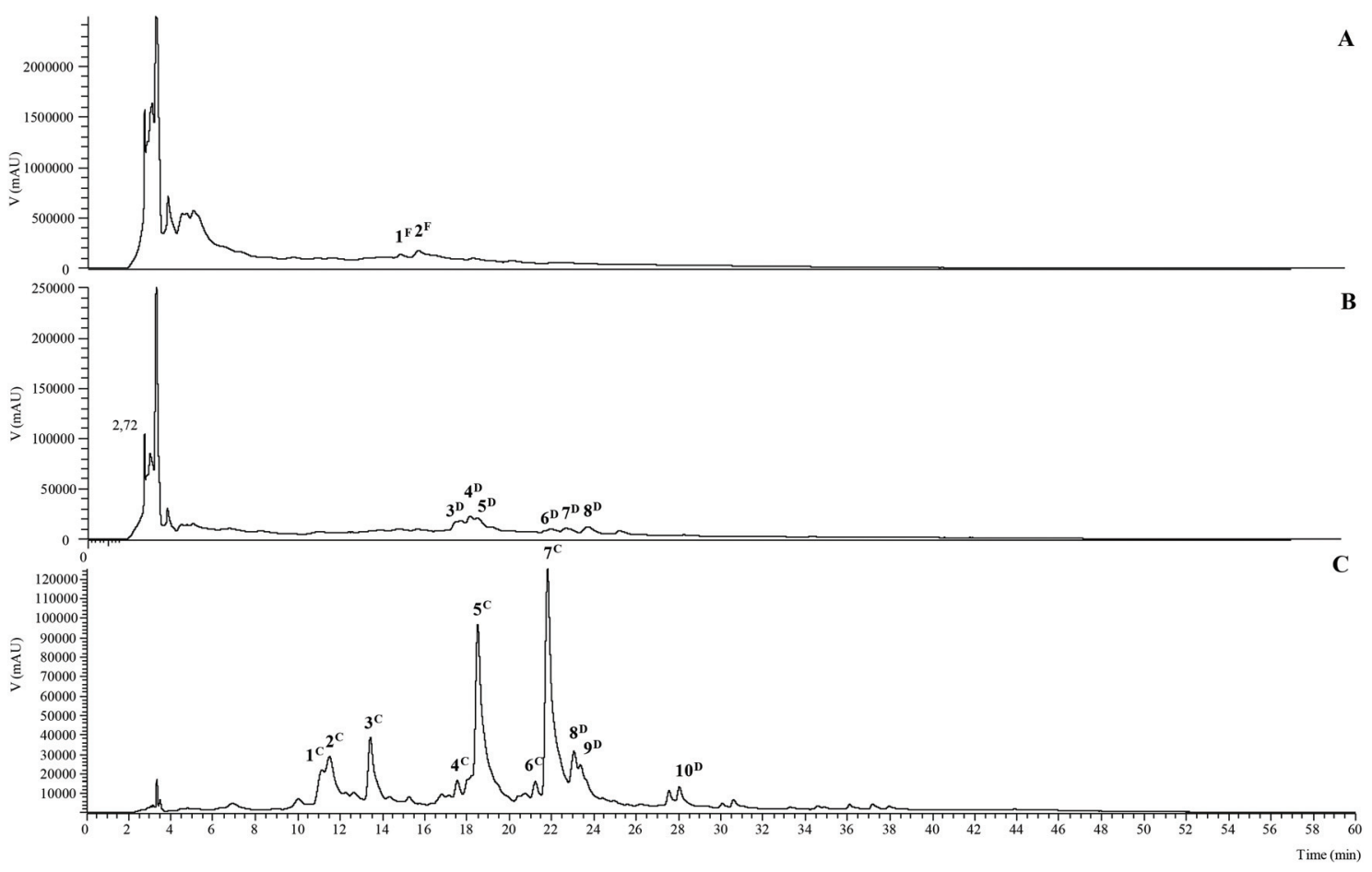

Fig. 5 Chromatographic profile of $R$. canina recorded at $280 \mathrm{~nm}(\mathrm{~A})$ and $370 \mathrm{~nm}$ (B), and E. rhamnoides recorded at $370 \mathrm{~nm}$ (C).

sterol/HDL-C, without any side effects in type-2 diabetic patients. These conclusions can be correlated with the fungal $\alpha$-glucosidase $\mathrm{IC}_{50}$ value obtained for the Rosa canina extract $\left(0.54 \pm 0.03 \mathrm{mg} \mathrm{mL}^{-1}\right)$. The $8 \mathrm{mg} \mathrm{mL}^{-1}$ rosehip extract inhibited mammalian $\alpha$-glucosidase at a value of $15 \pm 6 \%$.

Regarding the Elaeagnus rhamnoides fruit extract, the inhibitory activity of fungal $\alpha$-glucosidase is weak $\left(\mathrm{IC}_{50}=3.1 \pm\right.$ $0.2 \mathrm{mg} \mathrm{mL} \mathrm{m}^{-1}$ ). Also, the inhibition of mammalian $\alpha$-glucosidase is shown only at $8 \mathrm{mg} \mathrm{mL}-1$ concentration $(28 \pm 4 \%)$.

The data presented herein suggest that the Rosa canina pseudofruit extract can be used as a potent agent in the prevention and treatment of diabetes. Further studies are necessary to identify and isolate the compounds responsible for the $\alpha$-glucosidase inhibitory activity.

\section{Conclusion}

The drying of medicinal edible plant materials is a process which consists of various physical, chemical, and biological phenomena. They are very important to be understood in order to achieve high yields of bioactive compounds. The aim of this study was to optimize the drying process of the fruits from two species used in traditional medicine, Rosa canina and Elaeagnus rhamnoides. The optimal time of contact with hot air at a temperature of $60{ }^{\circ} \mathrm{C}$ for Rosa canina pseudofruits, resulting from the parameter analysis was $30.4 \mathrm{~h}$, whereas for Elaeagnus rhamnoides, it was 24.35 h. The extracts obtained exhibited high values of TPC, TFC, and antioxidant activity compared to the crude extracts. Moreover, the optimized rosehip extract showed the best $\alpha$-glucosidase inhibitory 
activity $\left(\mathrm{IC}_{50}=0.54 \pm 0.03 \mathrm{mg} \mathrm{mL} \mathrm{m}^{-1}\right)$. The rosehip and sea buckthorn extracts showed neither cytotoxic activity nor antiinflammatory capacity.

The data presented in this article represent a step forward towards the application of this process on an industrial-scale. Further studies are required in order to deeply understand the phenomena involved in the drying process of the studied plant materials.

\section{Conflicts of interest}

There are no conflicts of interest to declare.

\section{Acknowledgements}

This work was supported by a grant of the Romanian Ministry of Education and Research, CNCS - UEFISCDI, project number PN-III-P1-1.1-PD-2019-1245, within PNCDI III". The authors are grateful to the Foundation for Science and Technology (FCT, Portugal) for financial support through national funds FCT/ MCTES to CIMO (UIDB/00690/2020); the national funding by FCT, P. I., through the institutional scientific employment program-contract for L. Barros, Maria Inês Dias and C. Pereira's contracts; to FEDER-Interreg España-Portugal programme through the project TRANSCoLAB 0612_TRANS_CO_LAB_2_P; European Regional Development Fund (ERDF) through the Regional Operational Program North 2020, within the scope of Project Norte-01-0145-FEDER-000042: GreenHealth.

\section{Notes and references}

1 C. Chrubasik, B. D. Roufogalis, U. Müller-Ladner and S. Chrubasik, A Systematic Review on the Rosa canina Effect and Efficacy Profile, Phyther. Res., 2008, 22, 725-733.

2 F. Demir and M. Özcan, Chemical and technological properties of rose (Rosa canina L.) fruits grown wild in Turkey, J. Food Eng., 2001, 47, 333-336.

3 Z. Alam, Important Therapeutic Uses of Sea Buckthorn (Hippophae): A Review, J. Biol. Sci., 2004, 4, 687-693.

4 L. Ganju, Y. Padwad, R. Singh, D. Karan, S. Chanda, M. K. Chopra, P. Bhatnagar, R. Kashyap and R. C. Sawhney, Anti-inflammatory activity of Seabuckthorn (Hippophae rhamnoides) leaves, Int. Immunopharmacol., 2005, 5, 16751684.

5 X. Gao, M. Ohlander, N. Jeppsson, L. Björk and V. Trajkovski, Changes in antioxidant effects and their relationship to phytonutrients in fruits of sea buckthorn (Hippophae rhamnoides L.) during maturation, J. Agric. Food Chem., 2000, 48, 1485-1490.

6 G. Suryakumar, J. Purushothaman, P. Karan, P. Shweta, K. Ratan and S. RC, Hepatoprotective effects of sea buckthorn (Hippophae rhamnoides L.) against carbon tetrachloride induced liver injury in rats, J. Sci. Food Agric., 2007, 87, 930-944.
7 G. Suryakumar and A. Gupta, Medicinal and therapeutic potential of Sea buckthorn (Hippophae rhamnoides L.), J. Ethnopharmacol., 2011, 138, 268-278.

8 G. V. da Silva, B. A. S. Machado, W. P. de Oliveira, C. F. G. da Silva, C. P. de Quadros, J. I. Druzian, E. de Souza Ferreira and M. A. Umsza-Guez, Effect of Drying Methods on Bioactive Compounds and Antioxidant Capacity in Grape Skin Residues from the New Hybrid Variety "BRS Magna”, Molecules, 2020, 25, 1-15.

9 L. Bravo, Polyphenols: Chemistry, Dietary Sources, Metabolism, and Nutritional Significance, Nutr. Rev., 1998, 56, 317-333.

10 B. Romano, E. Pagano, V. Montanaro, A. L. Fortunato, N. Milic and F. Borrelli, Novel insights into the pharmacology of flavonoids, Phyther. Res., 2013, 27, 1588-1596.

11 M. S. Fernandez-Panchon, D. Villano, A. M. Troncoso and M. C. Garcia-Parrilla, Antioxidant Activity of Phenolic Compounds: From In Vitro Results to In Vivo Evidence, Crit. Rev. Food Sci. Nutr., 2008, 48, 649-671.

12 A. Brown, D. Anderson, K. Racicot, S. J. Pilkenton and E. Apostolidis, Evaluation of Phenolic Phytochemical Enriched Commercial Plant Extracts on the In Vitro Inhibition of $\alpha$-Glucosidase, Front. Nutr., 2017, 4, 56.

13 A. Mocan, M. Schafberg, G. Crisan and S. Rohn, Determination of lignans and phenolic components of Schisandra chinensis (Turcz.) Baill. using HPLC-ESI-ToF-MS and HPLC-online TEAC: Contribution of individual components to overall antioxidant activity and comparison with traditional antioxidant a, J. Funct. Foods, 2016, 24, 579-594.

14 A. Mocan, G. Zengin, M. Simirgiotis, M. Schafberg, A. Mollica, D. C. Vodnar, G. Crişan and S. Rohn, Functional constituents of wild and cultivated Goji (L. barbarum L.) leaves: phytochemical characterization, biological profile, and computational studies, J. Enzyme Inhib. Med. Chem., 2017, 32, 153-168.

15 S. M. F. Bessada, J. C. M. Barreira, L. Barros, I. C. F. R. Ferreira and M. B. P. P. Oliveira, Phenolic profile and antioxidant activity of Coleostephus myconis, (L.) Rchb. f.: An underexploited and highly disseminated species, Ind. Crops Prod., 2016, 89, 45-51.

16 A. Mocan, A. Diuzheva, S. Carradori, V. Andruch, C. Massafra, C. Moldovan, C. Sisea, J. P. Petzer, A. Petzer, S. Zara, G. D. Marconi, G. Zengin, G. Crişan and M. Locatelli, Development of novel techniques to extract phenolic compounds from Romanian cultivars of Prunus domestica L. and their biological properties, Food Chem. Toxicol., 2018, 119, 189-198.

17 A. Mocan, G. Crişan, L. Vlase, O. Crişan, D. C. Vodnar, O. Raita, A. M. Gheldiu, A. Toiu, R. Oprean and I. Tilea, Comparative studies on polyphenolic composition, antioxidant and antimicrobial activities of Schisandra chinensis leaves and fruits, Molecules, 2014, 19, 15162-15179.

18 A. Mocan, C. Moldovan, G. Zengin, O. Bender, M. Locatelli, M. Simirgiotis, A. Atalay, D. C. Vodnar, S. Rohn and G. Crișan, UHPLC-QTOF-MS analysis of bioactive constitu- 
ents from two Romanian Goji (Lycium barbarum L.) berries cultivars and their antioxidant, enzyme inhibitory, and real-time cytotoxicological evaluation, Food Chem. Toxicol., 2018, 115, 414-424.

19 F. Souilem, Â. Fernandes, R. C. Calhelha, J. C. M. Barreira, L. Barros, F. Skhiri, A. Martins and I. C. F. R. Ferreira, Wild mushrooms and their mycelia as sources of bioactive compounds: Antioxidant, anti-inflammatory and cytotoxic properties, Food Chem., 2017, 230, 40-48.

20 J. Takebayashi, N. Iwahashi, Y. Ishimi and A. Tai, Development of a simple 96-well plate method for evaluation of antioxidant activity based on the oxidative haemolysis inhibition assay (OxHLIA), Food Chem., 2012, 134, 606-610.

21 L. Lockowandt, J. Pinela, C. L. Roriz, C. Pereira, R. M. V. Abreu, R. C. Calhelha, M. J. Alves, L. Barros, M. Bredol and I. C. F. R. Ferreira, Chemical features and bioactivities of cornflower (Centaurea cyanus L.) capitula: The blue flowers and the unexplored non-edible part, Ind. Crops Prod., 2019, 128, 496-503.

22 R. M. V. Abreu, I. C. F. R. Ferreira, R. C. Calhelha, R. T. Lima, M. H. Vasconcelos, F. Adega, R. Chaves and M.-J. R. P. Queiroz, Anti-hepatocellular carcinoma activity using human HepG2 cells and hepatotoxicity of 6-substituted methyl 3-aminothieno[3,2-b]pyridine-2-carboxylate derivatives: In vitro evaluation, cell cycle analysis and QSAR studies, Eur. J. Med. Chem., 2011, 46, 5800-5806.

23 L. Barros, E. Pereira, R. C. Calhelha, M. Dueñas, A. M. Carvalho, C. Santos-Buelga and I. C. F. R. Ferreira, Bioactivity and chemical characterization in hydrophilic and lipophilic compounds of Chenopodium ambrosioides L., J. Funct. Foods, 2013, 5, 1732-1740.

24 S. T. Sakna, A. Mocan, H. N. Sultani, N. M. El-fiky, L. A. Wessjohann and M. A. Farag, Metabolites profiling of Ziziphus leaf taxa via UHPLC/PDA/ESI-MS in relation to their biological activities, Food Chem., 2019, 293, 233-246.

25 S. Erenturk, M. S. Gulaboglu and S. Gultekin, The thinlayer drying characteristics of rosehip, Biosyst. Eng., 2004, 89, 159-166.

26 T. Koyuncu, I. Tosun and N. S. Ustun, Drying kinetics and color retention of dehydrated rosehips, Drying Technol., 2003, 21, 1369-1381.

27 I. Koca, N. S. Ustun and T. Koyuncu, Effect of drying conditions on antioxidant properties of rosehip fruits (Rosa canina sp.), Asian J. Chem., 2009, 21, 1061-1068.

28 M. Araya-Farias, J. Makhlouf and C. Ratti, Drying of Seabuckthorn (Hippophae rhamnoides L.) Berry: Impact of Dehydration Methods on Kinetics and Quality, Drying Technol., 2011, 29, 351-359.

29 L. F. Gutiérrez, C. Ratti and K. Belkacemi, Effects of drying method on the extraction yields and quality of oils from quebec sea buckthorn (Hippophaë rhamnoides L.) seeds and pulp, Food Chem., 2008, 106, 896-904.

30 J. C. Sánchez-Rangel, J. Benavides, J. B. Heredia, L. Cisneros-Zevallos and D. A. Jacobo-Velázquez, The FolinCiocalteu assay revisited: Improvement of its specificity for total phenolic content determination, Anal. Methods, 2013, 5, 5990-5999.

31 I. Roman, A. Stǎnilǎ and S. Stǎnilǎ, Bioactive compounds and antioxidant activity of Rosa canina L. biotypes from spontaneous flora of Transylvania, Chem. Cent. J., 2013, 7, 1-10.

32 S. Ercisli, Chemical composition of fruits in some rose (Rosa spp.) species, Food Chem., 2007, 104, 1379-1384.

33 N. Montazeri, E. Baher, F. Mirzajani, Z. Barami and S. Yousefian, Phytochemical contents and biological activities of Rosa canina fruit from Iran, J. Med. Plants Res., 2011, 5, 4584-4589.

34 O. Rop, S. Ercişli, J. Mlcek, T. Jurikova and I. Hoza, Antioxidant and radical scavenging activities in fruits of 6 sea buckthorn (Hippophae rhamnoides L.) cultivars, Turk. J. Agric. For., 2014, 38, 224-232.

35 A. Pękal and K. Pyrzynska, Evaluation of Aluminium Complexation Reaction for Flavonoid Content Assay, Food Anal. Methods, 2014, 7, 1776-1782.

36 V. T. Tumbas, J. M. Čanadanović-Brunet, D. D. ČetojevićSimin, G. S. Ćetković, S. M. Dilas and L. Gille, Effect of rosehip (Rosa canina L.) phytochemicals on stable free radicals and human cancer cells, J. Sci. Food Agric., 2012, 92, 1273-1281.

37 N. Demir, O. Yildiz, M. Alpaslan and A. A. Hayaloglu, Evaluation of volatiles, phenolic compounds and antioxidant activities of rose hip (Rosa L.) fruits in Turkey, $L W T$ - Food Sci. Technol., 2014, 57, 126-133.

38 R. Guimarães, L. Barros, M. Dueñas, A. M. Carvalho, M. J. R. P. Queiroz, C. Santos-Buelga and I. C. F. R. Ferreira, Characterisation of phenolic compounds in wild fruits from Northeastern Portugal, Food Chem., 2013, 141, 3721-3730.

39 C. Turkben, V. Uylaser and B. Incedayi, Influence of traditional processing on some compounds of rose hip (Rosa canina L.) fruits collected from habitat in Bursa, Turkey, Asian J. Chem., 2010, 22, 2309-2318.

40 B.-S. Teng, Y. H. Lu, Z. T. Wang, X. Y. Tao and D. Z. Wei, In vitro anti-tumor activity of isorhamnetin isolated from Hippophae rhamnoides L. against BEL-7402 cells, Pharmacol. Res., 2006, 54, 186-194.

41 J. D. Nadpal, M. M. Lesjak, F. S. Šibul, G. T. Anačkov, D. D. Četojević-Simin, N. M. Mimica-Dukić and I. N. Beara, Comparative study of biological activities and phytochemical composition of two rose hips and their preserves: Rosa canina L. and Rosa arvensis Huds., Food Chem., 2016, 192, 907-914.

42 L. Barros, A. M. Carvalho, J. S. Morais and I. C. F. R. Ferreira, Strawberry-tree, blackthorn and rose fruits: Detailed characterisation in nutrients and phytochemicals with antioxidant properties, Food Chem., 2010, 120, 247-254.

43 U. K. Sharma, K. Sharma, N. Sharma, A. Sharma, H. P. Singh and A. K. Sinha, Microwave-assisted efficient extraction of different parts of Hippophae rhamnoides for the comparative evaluation of antioxidant activity and quantification of its phenolic constituents by reverse-phase 
high-performance liquid chromatography (RP-HP, J. Agric. Food Chem., 2008, 56, 374-379.

44 A. Kharazmi and K. Winther, Rose hip inhibits chemotaxis and chemiluminescence of human peripheral blood neutrophils in vitro and reduces certain inflammatory parameters in vivo, Inflammopharmacology, 1999, 7, 377-386.
45 M. Taghizadeh, A. A. Rashidi, A. A. Taherian, Z. Vakili, M. Sajad Sajadian and M. Ghardashi, Antidiabetic and Antihyperlipidemic Effects of Ethanol Extract of Rosa canina L. fruit on Diabetic Rats: An Experimental Study With Histopathological Evaluations, J. Evidence-Based Complementary Altern. Med., 2016, 21, NP25-NP30. 